On admission she looked pale and unwell but her temperature was normal. Abdominal examination showed lower abdominal tenderness, guarding, and rebound, particularly in the left iliac fossa. She also had an epigastric bruit, but no pulsatile mass was palpable and peripheral pulses were normal.

Investigations showed a haemoglobin concentration of $141 \mathrm{~g} / \mathrm{l}$, white cell count $24 \cdot 4 \times 10^{9} / 1$ (neutrophilia), platelet count $255 \times 10^{9} / 1$, erythrocyte sedimentation rate $33 \mathrm{~mm}$ in the first hour, and sodium concentration $129 \mathrm{mmol} / \mathrm{l}$; urea and electrolyte concentrations and amylase activity were normal. Stool microscopy and culture gave negative results. An erect chest radiograph was normal, showing no free subdiaphragmatic gas, but supine abdominal radiography suggested mucosal oedema of the transverse and distal colon. Sigmoidoscopy to $12 \mathrm{~cm}$ showed severely inflamed mucosa with contact bleeding, and multiple biopsy specimens were taken, which showed patchy areas of destruction with necrotic debris heavily laden with polymorphs. Intact, fairly normal mucosa was also seen, implying focal destruction. Tests for antibodies to nuclear and double stranded DNA were negative.

Ischaemic colitis was diagnosed, and she was treated conservatively with intravenous fluids and analgesia.
Over the next three days her condition improved, although her haemoglobin concentration fell by almost $30 \mathrm{~g} / \mathrm{l}$. Because of her history of systemic lupus erythematosus and her epigastric bruit she underwent mesenteric arteriography, which showed no abnormality. On day 5 , when her condition was improving, a barium enema gave normal results, reflecting rapid mucosal recovery.

She was discharged the next day: her bleeding had stopped, her condition was stable, and her epigastric bruit had disappeared. She made an uncomplicated recovery, and subsequent sigmoidoscopy and rectal biopsy gave normal results.

\section{Comment}

Because of her history of systemic lupus erythematosus we postulate that this patient had had a compromised circulation to the large bowel, which the mechanical effects of colonoscopy reduced to below a critical level. We found no evidence of large vessel disease, but one possibility must be that her small vessel circulation was compromised as a result of her connective tissue disease.

(Accepted 1 August)

\title{
Screening for carriers of cystic fibrosis among partners of people heterozygous for the disease
}

\section{Felix H Sennhauser, Sabina Liechti-Gallati, Hans Moser}

\section{Ostschweizerisches Kinderspital, CH-9006 St Gallen, Switzerland Felix H Sennhauser, MD, director, paediatric pulmonology}

\section{Universitäts-Kinderklinik,} Inselspital, Bern Switzerland

Sabina Liechti-Gallati, PHD, head, molecular genetics laboratory

Hans Moser, MD, director, clinical genetics service

Correspondence to: Dr Sennhauser.

Br Med f 1990;301:1081
Since the gene for cystic fibrosis was sequenced in $1989^{1}$ there has been much debate on the introduction of screening for carriers in the population. ${ }^{23}$ The most common mutation is the deletion of three base pairs $\left(\Delta F_{508}\right)$ in exon 10 of the transmembrane conductance regulator on cystic fibrosis chromosomes ${ }^{4}$; the 30 or more other mutations identified so far are very rare and thus much less suitable for screening. The frequency of $\Delta F_{508}$ in cystic fibrosis chromosomes varies among different populations and ethnic groups. In Switzerland this deletion is present in about $70 \%$ of cystic fibrosis chromosomes and the prevalence of carriers (q) is about 1 in 20 .

A serious problem with screening for carriers is that it will detect many couples in which only one partner carries $\Delta \mathrm{F}_{508}$, but heterozygosity in the other partner cannot be excluded without screening for the increasing number of other, rare mutations. General screening may be acceptable if the risk of having an affected child is less after screening than before. This means that with a prevalence of carriers of 1 in $20(5 \%)$ population screening should be postponed until at least $96 \%$ of the mutations can be detected. ${ }^{2}$

In high risk circumstances, however, such as marriages between a heterozygous relative of a patient with cystic fibrosis and an unrelated partner screening of both partners for $\Delta \mathrm{F}_{508}$ can help in genetic counselling and prenatal diagnosis. This is shown by the recent results of DNA analysis. in a Swiss family affected by cystic fibrosis.

\section{Subjects, methods, and results}

After his divorce the father of a patient with cystic fibrosis asked about the risk of having another child with cystic fibrosis as he wanted to marry an unrelated Swiss woman with no family history of cystic fibrosis. The risk before screening $(1 / 4 \times q)$ was $1 / 4 \times 1 / 20=1 / 80$.
If the woman was shown not to be a carrier of $\Delta F_{508}$ the risk of having a child with cystic fibrosis $(1 / 4 \times(1-a) \times q)$ would be reduced to $1 / 4 \times 0 \cdot 3 \times 1 / 20=1 / 267$, where $\mathrm{a}$ is the proportion of mutations screened for $(0 \cdot 7$ for $\left.\Delta F_{508}\right)$. The risk after screening would therefore be less than that before. The probability of $\Delta F_{508}$ not occurring in a partner unrelated to $\operatorname{him}((1-\mathrm{q}):(1-\mathrm{aq}))$ was $98 \cdot 4 \%$. Alternatively, if the woman was shown to be a carrier of $\Delta F_{508}$ (probability $1 \cdot 6 \%$ ) the risk of having an affected child would be $1 / 4$, but the reliability of prenatal diagnosis of cystic fibrosis in a future pregnancy would be $100 \%$.

After being told of these theoretical results the couple asked for an analysis of DNA. Unfortunately, this showed that both of them were carriers of $\Delta F_{508}$, and they decided to consider prenatal diagnosis.

\section{Comment}

We suggest that screening for $\Delta F_{508}$ should be offered to partners of people heterozygous for cystic fibrosis in countries in which the prevalence of carriers is about $5 \%$ and the prevalence of the deletion on cystic fibrosis chromosomes is about $70 \%$. Under these circumstances the risk of having a child with cystic fibrosis after screening would be less than that before screening for 49 out of 50 couples.

This study was supported by the Swiss National Science Foundation.

1 Rommens JM, Ianuzzi MC, Kerem B, et al. Identification of the cystic fibrosis gene: chromosome waking and jumping. Science 1989;245:1059-65.

2 Ten Kate LP. Carrier screening in CF. Nature 1989;342:131

3 Colten HR. Screening for cystic fibrosis. Public policy and personal choices. $N$ Engl f Med 1990; 322:328-9.

4 Kerem B, Rommens JM, Buchanan JA, et al. Identification of the cystic fibrosis gene: genetic analysis. Science 1989;245:1073-80.

(Accepted 23 August 1990)

\section{Correction}

Cost analysis of prophylaxis with antibiotics to prevent infected knee arthroplasty

Three authors' errors occurred in this paper by Dr Sten Bengtson and colleagues $(1989 ; 299: 719-20)$. In the table the total cost for patients with infection should be $\mathrm{Kr} 358166$ and not 353951 ; in the paragraph before the comment the cost saved with flucloxacillin is $\mathrm{Kr} 136617$ and with cephalexin is $\mathrm{Kr} 119459$ and not the other way round as published; and reference 2 was in fact published in the fournal of Bone and foint Surgery $[\mathrm{Br}]$ $(1984 ; 66: 580-2)$ and not in Clinical Orthopaedics. 